have only recently become available. Also, if multiple working groups with repreo sentatives from across the life sciences were established - similar to those set up by an effort to assess marine organisms called the Census of Marine Life - an IMI could be much broader in scope than any pre-existing programme.

Finally, an IMI would be able to solve the data sharing and intellectual-property issues that have been stumbling blocks for previous efforts, by organizing and controlling access to the metadata that are so essential for interpreting results, publishing papers and filing patents.

It is crucial that the IMI is launched quickly to avoid corrective actions having to be applied after-the-fact to national efforts. We invite private foundations that have been pivotal in mounting international research efforts to support an IMI. These include the Gordon and Betty Moore Foundation with its Marine Microbiology Initiative, the Alfred P. Sloan Foundation with its Census of Marine Life, the Kavli Foundation with its Brain Initiative, and the Bill \& Melinda Gates Foundation with its Global Health Program.

We also encourage national funding agencies to open up their programmes to international collaborations and to adopt any standards established by an IMI. Finally, we urge scientists to help make an IMI happen by sharing their data.

So much can be gained by creating an IMI. Further uncoordinated national microbiome programmes will almost certainly waste research efforts and taxpayers' money. Let's transcend national silos and gain universal insights that will benefit all humankind. -

Nicole Dubilier is a director at the Max Planck Institute for Marine Microbiology in Bremen, Germany. Margaret

McFall-Ngai is professor and director of the Pacific Biosciences Research Center at the University of Hawaii at Manoa, Honolulu, Hawaii, USA. Liping Zhao is professor of microbiology at Shanghai Jiao Tong University, Shanghai, China. e-mail:ndubilie@mpi-bremen.de

1. Alivisatos, A. P. et al. Science 350, 503-504 (2015).

2. Yarza, P. et al. Nature Rev. Microbiol. 12, 635-645 (2014)

3. La Scola, B. et al. Science 299, 2033 (2003)

4. Aagaard, K. et al. Sci. Transl. Med. 237, 237ra65 (2014).

5. Mukherji, A., Kobiita, A., Ye, T. \& Chambon, P. Cell 153, 812-827 (2013).

6. Heath-Heckman, E. A. C. et al. mBio 4, e00167-13 (2013)

7. Chen, W., Zhang, C. K., Cheng, Y., Zhang, S. \& Zhao, H. PLoS ONE 8, e70837 (2013)

8. Clemente, J. C. et al. Sci. Adv. 1, e1500183 (2015).

9. Schnorr, S. L. et al. Nature Commun. 5, 3654 (2014).

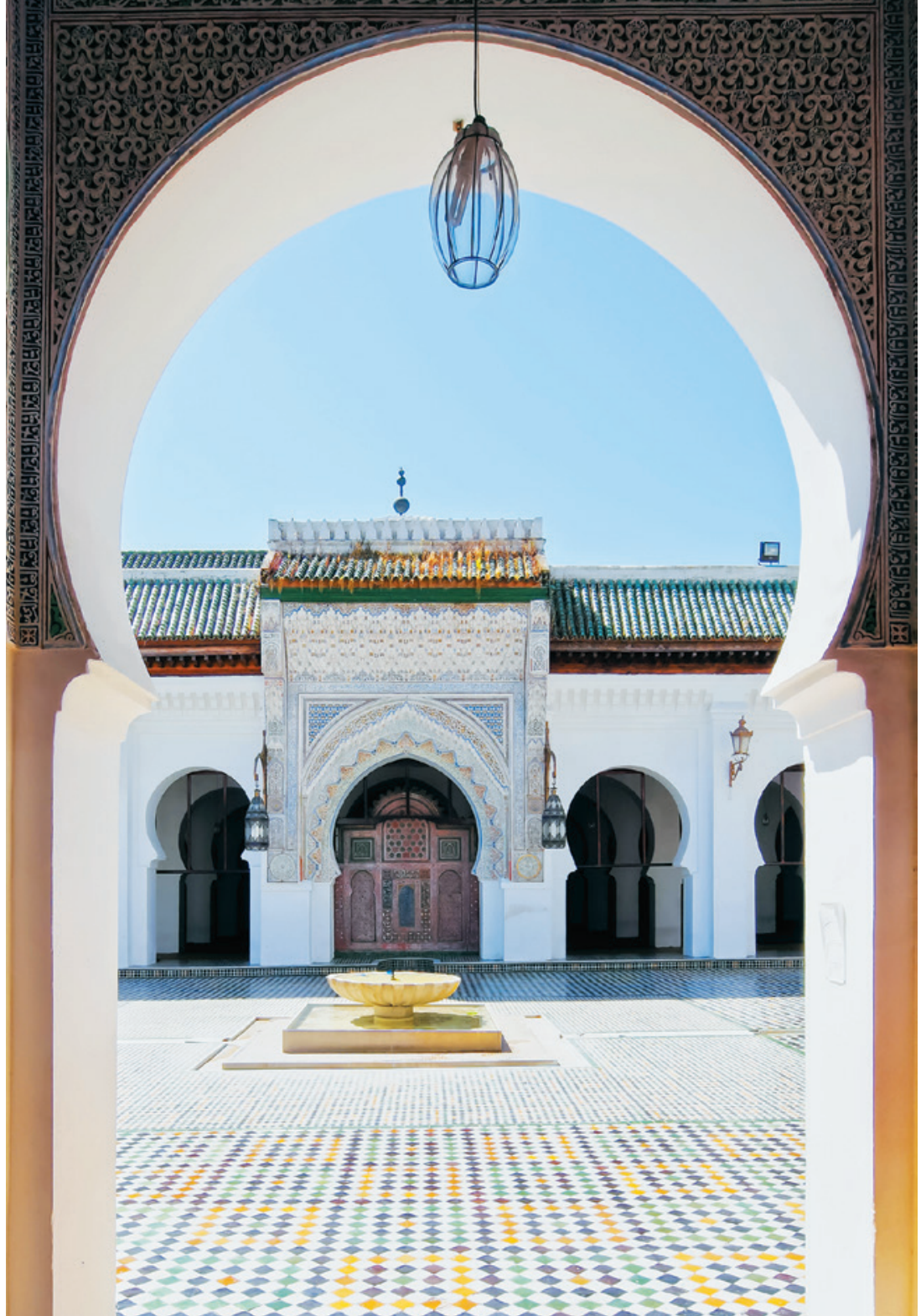

The world's oldest continually operational university was founded in Fes, Morocco, in AD 859.

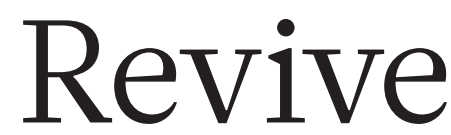

\title{
universities of the Muslim world
}

To boost science, higher-education institutes must give students a broad education and become meritocratic, say Nidhal Guessoum and Athar Osama.

$\mathrm{T}$ he Islamic civilization lays claim to the world's oldest continually operational university. The University of Qarawiyyin was founded in Fes, Morocco, in AD 859, at the beginning of an Islamic Golden Age. Despite such auspicious beginnings, universities in the region are now in dire straits, as demonstrated by a report we have authored, released this week (see go.nature.com/korli3).

The 57 countries of the Muslim world those with a Muslim-majority population, and part of the Organisation of Islamic Cooperation (OIC) - are home to nearly $25 \%$ of the world's people. But as of 2012, they had contributed only $1.6 \%$ of the world's patents, $6 \%$ of its academic publications, and $2.4 \%$ of 


\section{QUARTER DECK}

Investing on average $0.5 \%$ of their gross domestic product (GDP) on research and development (less than one-third of the global average), the Organisation of Islamic Cooperation (OIC) countries' science output lags, as measured by patents and publications.

OIC countries Rest of the world

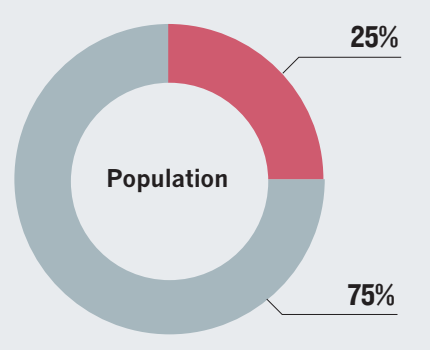

$2.4 \%$

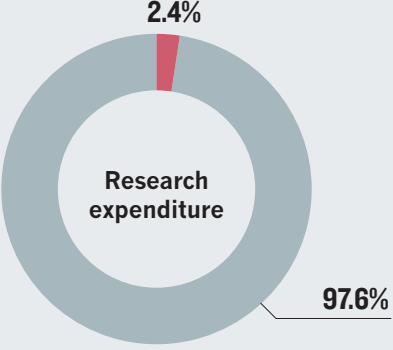

$1.6 \%$

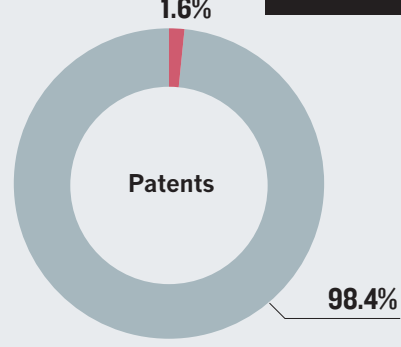

$6 \%$

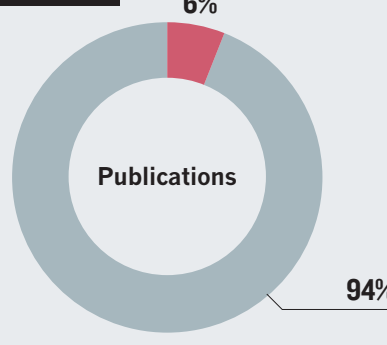

the global research expenditure ${ }^{1,2}$ (see 'Quarter deck'). There have been only three Nobel laureates in the sciences from OIC countries; today these nations host fewer than a dozen universities in the top 400 of the many world rankings, and none in the top 100.

To assess this situation, for the past two years we have led an international non-governmental and non-partisan task force of experts, formed by the Muslim World Science Initiative. The task force was chaired by Zakri Abdul Hamid, science adviser to the prime minister of Malaysia. It included a dozen experts and scholars - including policymakers, vice-chancellors, professors, and science communicators - from around the world.

Our work confirmed many widely known problems, as highlighted by reports such as the Royal Society's 2014 Atlas of Islamic World Science and Innovation ${ }^{2}$. For example, OIC countries on average invest less than $0.5 \%$ of their gross domestic product (GDP) on research and development (R\&D). Only Malaysia spends slightly more than $1 \%$ (the world average is $1.78 \%$; most advanced countries spend $2-3 \%)$. Students in the Muslim world who participate in standardized international science tests lag well behind their peers worldwide, and the situation seems to be worsening ${ }^{3,4}$.

Our report highlights an even more problematic situation. University science programmes are using narrow content and outdated teaching methods. In most OIC countries, students are channelled into science or non-science streams around the age of 14, and their education thereafter is completely binary: science and technology students receive little in the way of humanities, social-science, language or arts education, and vice versa. Only one university in the region offers a programme in 'science and technology studies': the University of Malaya in Kuala Lumpur.

To become beacons in society, OIC universities need to revitalize their teaching methods and meld science with liberal arts such as history and philosophy. For universities to

become truly meritocratic, they must develop new ways of assessing faculty members to reward valuable research, teaching and outreach. And for this to happen, governments must give universities more autonomy.

\section{QUANTITY AND QUALITY}

Our task force gathered data on science production for the 20 OIC countries that together have represented more than $90 \%$ of OIC scientific productivity over the past two decades. From the period 1996-2005 to 2006-15, most countries doubled or tripled their production of science papers. Qatar's output rocketed by a factor of 7.7, and Iran's by 7.6. But the number of scientific papers produced remains below the average of countries with similar GDP per capita. We found an average of 4.2 papers per dollar of GDP per capita for our OIC sample in the most recent decade, compared to an average of 8.6 for a group of 4 peer countries such as Brazil, Spain, South Korea, South Africa and Israel (see Supplementary Information; go.nature. com/4o3itm).

Papers from these OIC countries are cited less frequently than those from other

\section{"Science classes} themselves have serious problems." nations. The average was 5.7 citations per paper for 2006-15, compared with 9.7 for South Africa and 13.8 for Israel, countries with a comparable GDP per capita. A list of the 100 most-cited papers since 1900 has none with a lead author from a Muslim-majority nation (see Nature 514, 550-553; 2014).

Scientific research must be relevant and responsive to society's intellectual and practical needs. This dual goal seems to be out of sight - and often out of consideration - for most academic institutions in the region.

For scientists and engineers to be creative, innovative and able to engage with questions of ethics, religion and the wider social purpose of research, students must receive a broad, liberal-arts-style education ${ }^{5}$. A few institutions attempt to relate their students' learning to their cultural backgrounds and contemporary knowledge. In the early 1970s, Tehran's Sharif University of Technology began a rich programme melding Islamic history, philosophy and culture with science and engineering. Its graduate programme in the philosophy of science remains the only one in the OIC that we are aware of. It is perhaps no coincidence that the most recent Times Higher Education world university rankings named Sharif University as the top Iranian university and number eight in the OIC.

In recent years, US-style liberal-arts establishments have been set up in the region, modelled on the long-running and respected American University of Beirut and the American University in Cairo. One such is the American University of Sharjah (AUS) in the United Arab Emirates (UAE), which this year ranked seventh in the QS Rankings of universities in the 22 Arab countries. Fully homegrown and self-funded and with no formal affiliation with a US institution, the AUS requires science and engineering students to take roughly one-third of their required 40 or so courses in humanities, social sciences, language and communication.

Habib University, founded last year in Karachi, Pakistan, also follows this model. Here, science and engineering students must take courses such as 'Understanding Modernity' and 'Hikma 1 \& 2' - a two-course sequence that translates as 'traditional wisdom' - as well as many others that seek to create rounded rather than narrow engineering and science professionals. Other educational establishments should follow suit.

\section{CURRICULAR INNOVATION}

Science classes themselves have serious problems. The textbooks used in OIC universities are often imported from the United States or Europe. Although the content is of a high standard, they assume a Western experience and use English or French as the language of instruction. This disadvantages many students, and creates a disconnect between their 


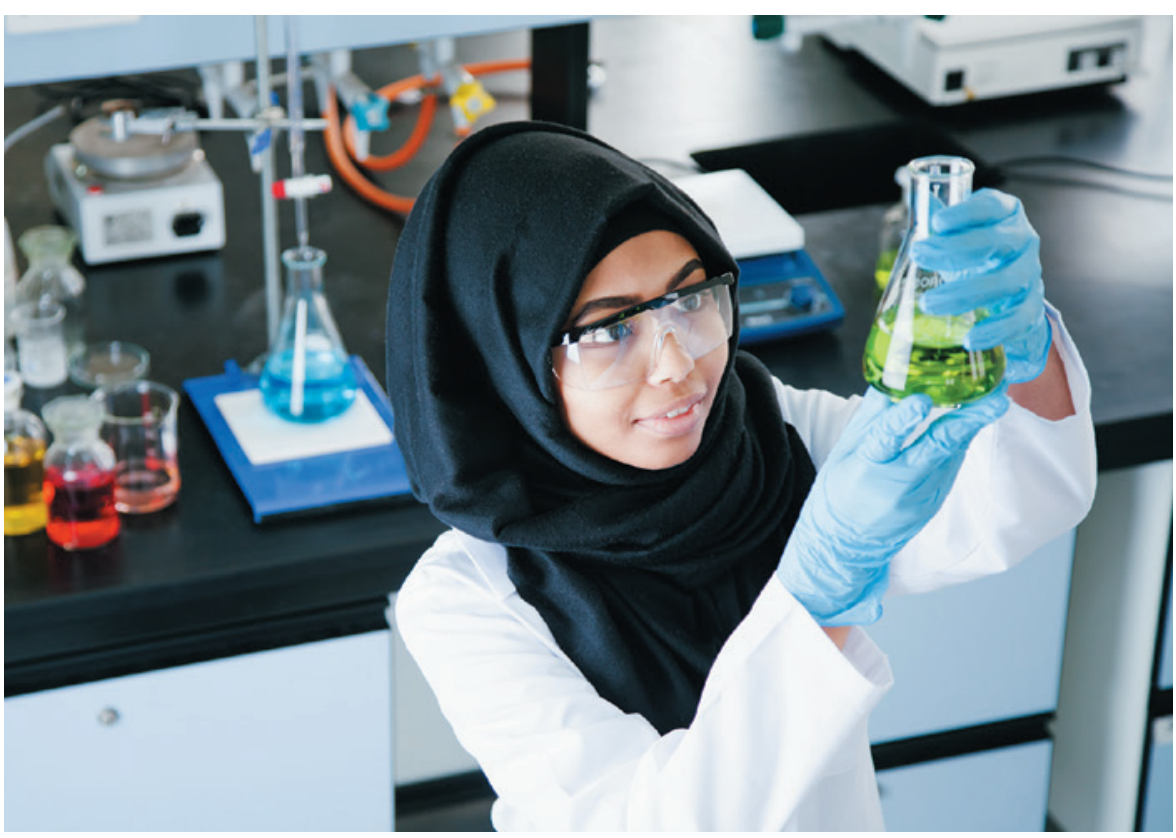

Science students at the American University of Sharjah must take humanities and social-science courses.

education and culture. To encourage the production of higher-quality, local textbooks and other academic material, universities need to reward staff for producing these at least as much as they do for research publication.

Some basic facts are seen as controversial, and marginalized. Evolution, for example, is usually taught only to biology students, often as "a theory", and is rarely connected to the rest of the body of knowledge. One ongoing study has found, for example, that most Malaysian physicians and medical students reject evolution (see go.nature.com/38cswo). Evolution needs to be taught widely and shown to be compatible with Islam and its culture $^{6}$. Teaching the philosophy and history of science would help, too.

The global consensus is that enquiry-based science education fosters the deepest understanding of scientific concepts and laws. But in most OIC universities, lecture-based teaching still prevails. Exceptions are rare. One is the Petroleum Institute, an engineering university in Abu Dhabi, UAE, where the faculty has created a hands-on experience with positive results on student interest and enrolment, particularly of women.

Another problem is that faculty members rarely — if ever - receive any training or evaluation in pedagogy. This is true elsewhere in the world, but change is harder in many OIC nations. In most, curriculum changes, faculty appointments and promotions are set by ministry rules and decided by centralized commissions and bureaucracies. This leaves little room for universities to innovate.

\section{THE WAY FORWARD}

Universities in OIC nations need to be granted more autonomy to transform themselves into meritocracies that strive

for scientific excellence and then lead rather than follow the winds of change towards greater transparency and meritocracy within their societies.

Universities need to promote the right metrics, so that they do not inadvertently encourage plagiarism and junk science through pressure to publish. The region needs consistent data on science student and faculty profiles, curricula, pedagogy, language of instruction and so on, akin to what the Institute of Statistics of the United Nations Educational, Scientific and Cultural Organization collects - but at a fine-grained, university level. This is a task that must be undertaken by national or transnational bodies, such as the Islamic World Academy of Sciences (IAS) or the Islamic Educa-

tional, Scientific and Cultural Organization (ISESCO).

We also call for reform of science curricula and pedagogy. Universities need to deliver more multi-

\section{"Professors need to be free to teach topics that are not tightly regulated by ministries."} disciplinary, explora-

tory science education. A good start would be training for university teachers, with workshops on new tools and approaches. Barriers need to be broken between departments and colleges and new programmes constructed. Professors need to be free to teach topics that are not tightly regulated by ministries.

There are grassroots efforts across the Muslim world to stimulate curiosity about science among students of all ages, operating without much government support. Ahmed Djebbar, an emeritus science historian at the University of Lille in France, has constructed an online, pre-university-level course called 'The Discoveries in Islamic Countries' available in three languages ${ }^{7}$, which relates science concepts to great discoveries and stories from the Islamic Golden Age. Such courses should be scaled up and shared by many institutions.

Universities will need to implement reforms individually. We hope that the inspiration from a few islands of excellence will, in time, turn the tide of public and political opinion. There is precedent. In Pakistan, two private universities established in the 1980s - the Aga Khan University and Hospital in Karachi and Lahore University of Management Sciences - revolutionized medical and business education within a decade of their creation. Students elsewhere began demanding the standard set by these educational pioneers. The same can be done for science.

Our task force is putting out an open call for universities across the Muslim world to join a voluntary Network of Excellence of Universities for Science (NEXUS), to be launched early next year. This peer group will be managed by the task force and housed in science adviser Zakri's office. We plan for NEXUS to run summer schools for university administrators, to monitor the progress of reforms at participating universities, and to issue a peer report card that will assess the performance of the universities in meeting milestones, thus recognizing and inspiring further improvements. True transformation will require much broader action from ministries, regulators and funding agencies, and these may be the most resistant to change.

Without tough reforms, the dream of a scientific revival in the Muslim world will remain just that.

Nidhal Guessoum is professor of physics and astronomy at the American University of Sharjah, United Arab Emirates.

Athar Osama is an honorary senior associate at the UCL Institute of Education, London, UK, and the founder of the Muslim World Science Initiative.

e-mails:nguessoum@aus.edu; athar.osama@gmail.com

1. Royal Society. A New Golden Age? The Prospects for Science and Innovation in the Islamic World (Royal Society, 2010).

2. Royal Society. The Atlas of Islamic World Science and Innovation (Royal Society, 2014).

3. Martin, M. O., Mullis, I. V. S., Foy, P. \& Stanco, G. M. TIMSS 2011 International Results in Science (TIMSS \& PIRLS International Study Center, 2012).

4. OECD. PISA 2012 Results in Focus (OECD, 2014).

5. Bloom, D. E. \& Rozovsky, H. Liberal Educ. 89, 16-23 (2003).

6. Guessoum, N. Islam's Quantum Question: Reconciling Muslim Tradition and Modern Science (IB Tauris, 2011).

7. Djebbar, A. The Discoveries in Islamic Countries (Editions le Pommier, 2009). 